\title{
Mortality and incidence of cancer of workers in the man made vitreous fibres producing industry: an international investigation at 13 European plants
}

\author{
R SARACCI, ${ }^{1}$ L SIMONATO, ${ }^{1}$ E D ACHESON,${ }^{2}$ A ANDERSEN, ${ }^{3}$ P A BERTAZZI, ${ }^{4}$ \\ J CLAUDE, ${ }^{5} \mathbf{N}$ CHARNAY,${ }^{6} \mathrm{~J}$ ESTEVE, ${ }^{6} \mathrm{R}$ R FRENTZEL-BEYME, ${ }^{5} \mathrm{M} J \mathrm{G}$ GRDNER, ${ }^{2}$ \\ O M JENSEN, ${ }^{7}$ R MAASING,${ }^{8} \mathrm{~J}$ H OLSEN, ${ }^{7}$ L TEPPO, ${ }^{9}$ P WESTERHOLM,${ }^{10}$ AND \\ C ZOCCHETTI ${ }^{4}$
}

From the Analytical Epidemiology Unit, ${ }^{1}$ International Agency for Research on Cancer, Lyon, France; MRC Environmental Epidemiology Unit, ${ }^{2}$ Southampton, UK; Norwegian Cancer Registry, ${ }^{3}$ Oslo, Norway; Institute of Occupational Health "L Devoto," University of Milan, Italy; German Cancer Research Centre, ${ }^{5}$ Heidelberg, Federal Republic of Germany; Biostatistics Unit, ${ }^{\circ}$ IARC, Lyon, France; Danish Cancer Registry, Copenhagen, Denmark; Kabi AB Drug Co-operation, ${ }^{8}$ Stockholm, Sweden; Finnish Cancer Registry, ${ }^{9}$ Helsinki, Finland; and Swedish Trade Union Confederation, ${ }^{10}$ Stockholm, Sweden

ABSTRACT A total of 25146 workers at 13 plants producing man made mineral fibres (MMMF) in seven European countries (Denmark, Finland, Federal Republic of Germany, Italy, Norway, Sweden, and United Kingdom) were studied in a historical cohort investigation. At 12 of the 13 plants an environmental survey was carried out to determine present day concentrations of airborne man made mineral fibres that showed levels of respirable fibres usually below $1 \mathrm{f} / \mathrm{ml}$ and most commonly in the range 0.01 to $0.1 \mathrm{f} / \mathrm{ml}$. Workers were entered into the cohort at the moment of their first employment at one of the 13 factories (which started to operate between 1900 and 1955), and were followed up to at least 31 December 1977. Three per cent of the workers were lost to follow up. National death rates and national cancer incidence rates, where applicable, were used for each of the seven countries for comparison with the workers' cohort. A single death from mesothelioma was reported out of a total of 309353 person-years of observation. No consistent differences (within and between plants) were noted between observed and expected numbers concerning individual causes of death or individual cancer sites, apart from lung cancer. For this cause a tendency was observed for the standardised mortality ratio (SMR) to increase with time from first employment. When the data from all the plants were pooled a statistically significant raised SMR of 192 (17 observed, 8.9 expected; $95 \%$ confidence interval 117-307) appeared in the group with 30 years or more since first employment. The relevance of this finding, to which different factors including uncontrolled confounders such as smoking habits may have contributed, cannot be established at present. The result is suggestive, however, of an increased risk associated with the man made mineral fibres working environment of 30 or more years ago.

Man made vitreous fibres (MMVF), usually referred to as man made mineral fibres (MMMF), include different inorganic synthetic wool products (slag wool, rock wool, glass wool) widely used as thermal and acoustic insulation material and as filament products used for textile manufacturing and for the reinforcing of plastic materials. Production of

Received 9 January 1984

Accepted 6 March 1984
MMMF had reached an estimated world annual total of $4.5 \mathrm{~m}$ tons in 1973 , thus being close to that of asbestos.' Biologically, experiments in animal systems have indicated that MMMF may have pathogenic action $\mathrm{s}^{2-4}$ (fibrogenic and carcinogenic), while pertinent epidemiological observations on pulmonary fibrosis (or more generally, chronic respiratory diseases) and on respiratory cancer in exposed subjects have been limited until recently. ${ }^{5}$ 
We present and discuss here the results of an international epidemiological investigation, involving 13 factories producing MMMF in seven Western European countries, carried out with the coordination of the International Agency for Research on Cancer.

\section{Methods}

\section{SELECTION OF PLANTS}

All 72 MMMF production plants included in early 1976 in the roster of companies belonging to the European Insulation Manufacturers Association
(EURIMA) and to the Comite International de la Rayonne et des Fibres Synthetiques (CIRFS) in 15 European countries were considered as candidates for selection in a historical cohort study of their workforce. Criteria for selection were:

(1) No loss or destruction of personnel records; total cohort identifiable;

(2) MMMF production process operating for at least 20 years;

(3) Facilities for follow up available with regard to mortality and, whenever possible, cancer incidence; and

(4) Plants with a history of processing asbestos

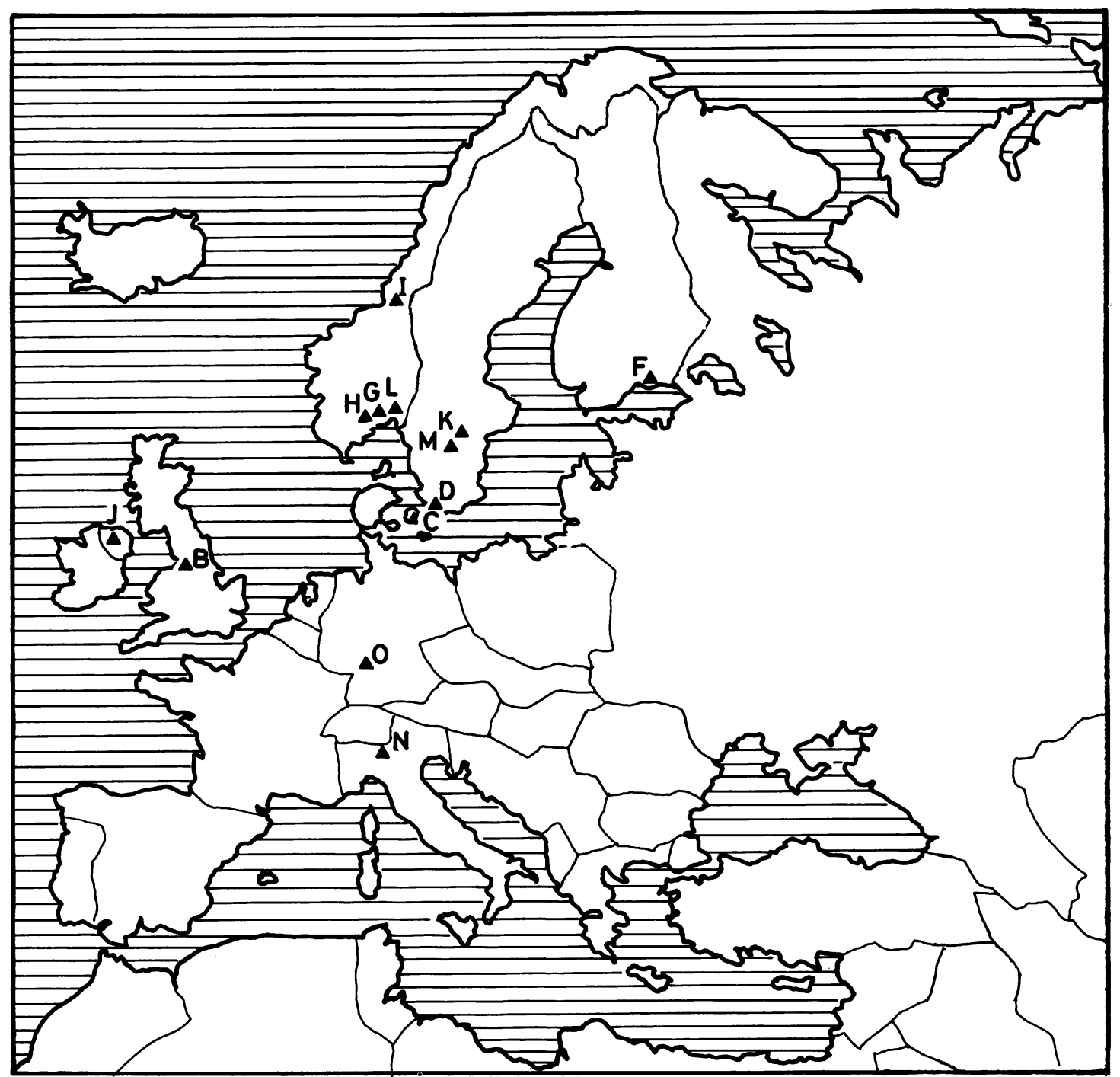

Geographical distribution of man made mineral fibre producing plants included in the study. 
materials excluded.

These requirements, together with other information of a general nature (plant address, approximate present workforce) were ascertained in a preliminary way by a mailed questionnaire. This was followed up by a direct site visit and inquiry at each plant: individual visits were made to 64 plants, eight having been discarded on the basis of the questionnaire reply only as obviously unsuitable for a historical study. As a result of the application of the selection criteria, 13 factories in seven countries (Denmark, Finland, Federal Republic of Germany, Italy, Norway, Sweden, United Kingdom (figure)) were chosen for the study. They included seven rock wool factories (labelled C, G, H, I, K, M, O), four glass wool factories (B, D, F, L), and two factories producing continuous glass filament $(\mathrm{J}$ and $\mathrm{N}): \mathrm{N}$ had actually produced glass wool up to 1962 . The letter labels of each factory correspond to those used in the environmental survey. ${ }^{6}$ The 13 factories, which started operations between 1900 and 1955 , represented $18 \%$ of the total in the initial roster and $20 \%$ of the workforce in 1976.

\section{ENVIRONMENTAL SURVEY}

At 12 of the 13 plants a team from the Institute of Occupational Medicine, Edinburgh, conducted an environmental survey to measure present concentrations of fibres in air samples collected by personal samplers carried during an eight hour shift by workers operating in different jobs and plant areas.

No survey could be conducted at plant $O$ which was closed at the time of the study.

\section{EPIDEMIOLOGICAL INVESTIGATION}

In each of the seven countries a national research team of investigators undertook, with IARC coordination, two main functions:

(1) Supervision of identification and transcription of workers' nominal rolls and job history records performed at the personnel offices at each plant. A worker was considered to have entered the cohort at the date of his first employment in one of the 13 factories, each of which had a different opening date ranging from 1900 to 1955 . At four plants (B, D, K, $M)$, after an initial examination of the available records, workers employed for less than one year were excluded from the cohort owing to the low quality of recorded information in the factory files (missing identification items, dates, incomplete occupational histories, etc).

(2) Follow up of workers with ascertainment of vital status, cause of death, and, whenever possible, occurrence of cancer as derivable from cancer registries. Follow up was implemented either through a central national facility, the national death register, for example, or, when such a facility was not accessible, through a peripheral mechanism of multiple contacts and inquiries such as the town hall offices of a worker's last residence. All workers were followed up at least until 31 December 1977. In factories B and $J$ the data collection was extended to 31 December 1978 and for factories $\mathrm{N}$ and $\mathrm{O}$ to 31 December 1979.

Whatever the tracing mechanism, causes of death were ascertained as on the death certificate, and the diagnosis of cancer as in the cancer registry files and coded according to the version of the International Classification of Diseases (ICD) in use at the national level at the time of the event (death or cancer diagnosis). For the purposes of the presentation of results all codes have been converted to those of the 7th version of the ICD. National death rates specific for calendar period, cause, sex, and age, and national cancer incidence rates (when applicable) specific for calendar period, site, sex, and age, were obtained for each of the seven countries in the study, either by the national collaborating investigators or, if more expedient, computed by IARC using the WHO mortality data bank. Quinquennial intervals were used both for age and for calendar year grouping.

The results, as presented below, derive from the analysis of the data performed centrally at IARC. A modified life table procedure and computing program were used to calculate person-years at risk, expected number of deaths (or expected number of cases of cancer) on the basis of the national reference rates, and ratios (standardised mortality ratio (SMR) or standardised incidence ratios (SIR)) between observed deaths (or cases of cancer) and those expected multiplied by 100 . Ninety five per cent confidence limits for SMR and SIR were computed based on the Poisson distribution. Personyears and expected values were computed starting from the first year, variable from country to country, in which the national reference rates were available. For mortality rates the starting year ranged from 1942 (Italy) to 1953 (Finland and Norway) whereas for cancer incidence rates it ranged from 1943 (Denmark) to 1958 (Sweden). Within each factory jobs/plant areas were grouped into six main occupational categories: not specified; office; preproduction (including workers at the raw materials reception, weighing, and mixing sections of a factory); production (including workers at the raw material melting furnace and at the glass fiberisation and fibre curing section); secondary processes (including workers at a variety of dry processes, shaping the primary fibre product into forms usable in applications); and maintenance (in any section of the factory). The present day mean concentration of 
respirable fibres was calculated for each category, based on the result of the environmental survey. Fibres, counted by phase-contrast microscopy, were defined as particles longer than $5 \mu \mathrm{m}$ and with a length to diameter ratio of 3 to 1 or more, respirable fibres being considered as those with a diameter $<3 \mu \mathrm{m}$. For each worker a cumulative exposure index was created, multiplying the present day mean concentration of the respirable fibres for each occupational main categories by the duration of stay of the worker in that group, and by totalling the products. This was used to explore the existence of exposure (= cumulative index)-response (= SMR) relationships for male cases of lung cancer. In addition, the exposure-response relationship was examined through a case-control analysis of duration of exposure in dead cases of lung cancer and controls surviving to the case (up to a maximum of 40 per case) matched to him by factory and date of birth ( \pm 2 years). Duration of exposure of the dead cases was compared with that of the controls up to the time of death of the former.

\section{Results}

\section{CHARACTERISTICS OF THE WORKING \\ POPULATION}

The total number of workers in the cohort, the total number of recorded deaths, and the numbers and percentages of workers lost to follow up for each factory and separately by sex, are given in table 1 . A small proportion of the workforce, less than $1 \%$ on average, could not be included in the cohort because one or more basic items (date of birth, sex, date of first employment) was missing. The rock wool type of production is the most represented in the study ( $50 \%$ of the total workforce). The range of the workforce in the individual factories is large, varying from 485 in factory $\mathrm{K}$ to 5369 in factory $\mathrm{C}$. Men are largely predominant with a $M$ to $F$ ratio of $4 \cdot 7: 1$. The percentages of workers lost to follow up range from 0 to about $10 \%$, the lowest percentages having been achieved where a central national tracing facility was available and the workforce was relatively small in size and included few foreign workers. Conversely, a sizeable number of short term immigrant workers affected the follow up of factory $O$.

The overall mean duration of employment was 5.1 years, ranging from 2.3 years to 11.3 for the workforce of different factories. The overall median duration was 2.2 years (range 0.5 to 4.6 years).

The number of person-years accumulated in the cohort for the mortality analysis and for the cancer incidence analysis for men and women and for three time intervals since first employment is shown in table 2. Of the total of 309353 person-years for both sexes computed for mortality 9074 occurred 30 or more years after first employment. In this time interval 191 deaths took place.

\section{CHARACTERISTICS OF THE WORKING \\ ENVIRONMENT}

The results of the environmental survey have been reported elsewhere by Ottery et al. ${ }^{6}$ For the six plants producing rock wool the average concentration of respirable fibre for the main occupational groups was $0.04 \mathrm{fibres} / \mathrm{ml}$; the corresponding concentration for the four glass wool plants was 0.02 fibres $/ \mathrm{ml}$. The average respirable fibre concentration for the same occupations at the two continuous fibre plants was $0.006 \mathrm{f} / \mathrm{ml}$. The highest fibre concentrations were usually observed in secondary processes, particularly in plants producing fine fibres. For these secondary processes the group average fibre concentration ranged from $0.03 \mathrm{f} / \mathrm{ml}$ to $0.45 \mathrm{f} / \mathrm{ml}$. The highest respirable fibre concentration recorded

Table 1 Total number of workers: deaths and lost to follow up by factory and by sex

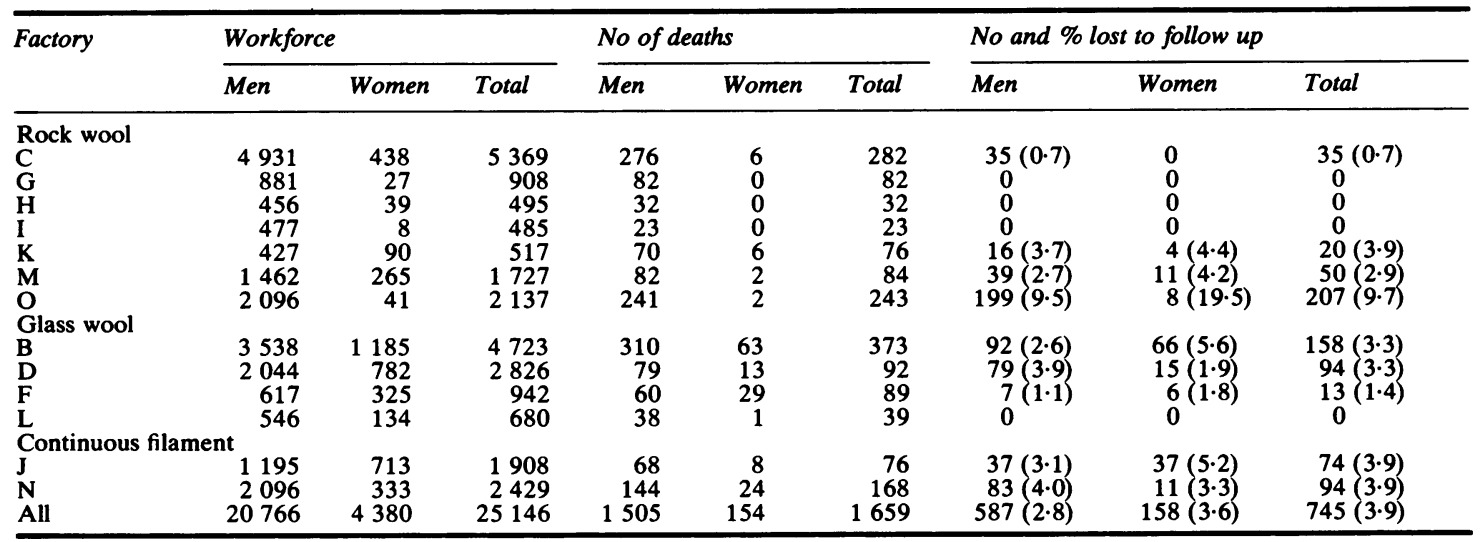


Table 2 Person-years at risk by time since furst employment, by factory, and by sex (for mortality and incidence analysis)

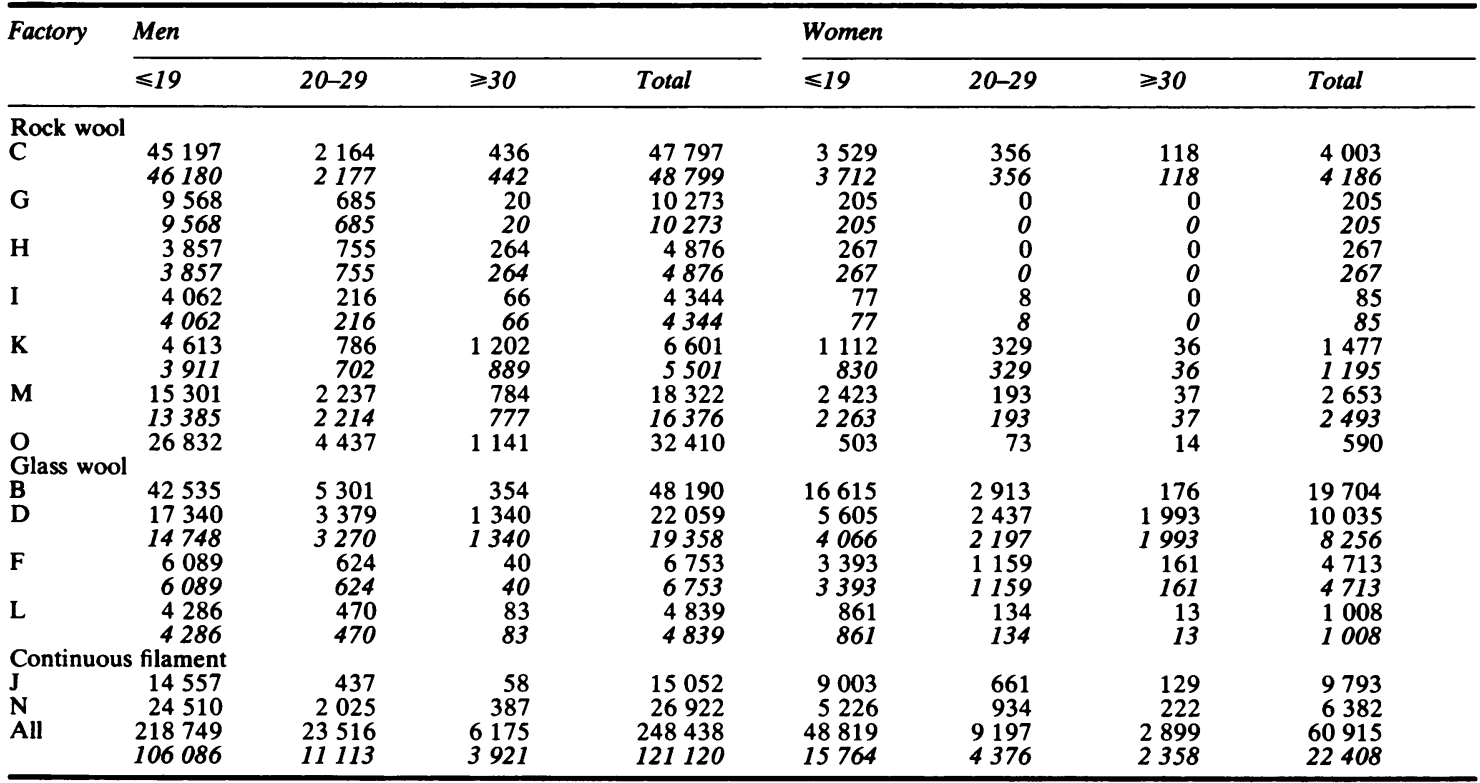

Table 3 Mortality analysis by cause of death for the total period of observation (men)

\begin{tabular}{|c|c|c|c|c|}
\hline Cause of death (7th ICD revision) & Obs & Expected & $S M R$ & $95 \%$ Conf int \\
\hline $\begin{array}{l}\text { All causes } \\
\text { All neoplasms (140-205) } \\
\text { Buccal cavity and pharynx (140-148) } \\
\text { Oesophagus (150) } \\
\text { Stomach (151) } \\
\text { Intestine, except rectum }(152,153) \\
\text { Rectum (154) } \\
\text { Larynx (161) } \\
\text { Trachea, bronchus, and lung }(162,163) \\
\text { Prostate (177) } \\
\text { All other and unspecified sites }(155-160,164,165,170, \\
175,176,178-181,190-199) \\
\text { Leukaemia and aleukaemia }(204) \\
\text { Lymphosarcoma and other neoplasms of lymphatic } \\
\text { and haematopoietic system (200-203, 205) } \\
\text { Benign neoplasms and neoplasms of unspecified } \\
\text { nature (210-239) } \\
\text { Circulatory system (400-468) } \\
\text { Respiratory system (470-527) } \\
\text { Bronchitis, chronic and unqualified, asthma (501, } \\
502,241,527 \cdot 1) \\
\text { Accidents, poisonings, and violence (E810-E999) } \\
\text { All other causes }\end{array}$ & $\begin{array}{r}1505 \\
373 \\
6 \\
8 \\
46 \\
24 \\
16 \\
7 \\
109 \\
14 \\
115 \\
12\end{array}$ & $\begin{array}{r}1666.4 \\
391.9 \\
6.6 \\
8.0 \\
51.3 \\
25.6 \\
17.8 \\
4.2 \\
102.6 \\
25.9\end{array}$ & $\begin{array}{r}90 \\
95 \\
91 \\
100 \\
90 \\
94 \\
90 \\
167 \\
106 \\
54\end{array}$ & $\begin{array}{l}86-95 \\
86-105 \\
33-198 \\
43-197 \\
66-120 \\
60-139 \\
52-146 \\
67-345 \\
87-128 \\
30-91 \\
83-121 \\
43-144 \\
45-127\end{array}$ \\
\hline
\end{tabular}

among all samples was $1.89 \mathrm{f} / \mathrm{ml}$ in one specialised section of a secondary process. All these airborne fibre concentrations reflect present day conditions: environmental data from one production line operating without "binders" (which favour fibre adhesiveness), as practised in the early periods of the industry, suggest that in the past concentrations may have been higher (one order of magnitude?). The differences between the average respirable con- centration in the different production processes (rock wool, glass wool, continuous filament) provide a rationale for a separate analysis of the corresponding epidemiological data.

\section{MORTALITY}

In table 3 the number of observed and expected deaths, their ratios (SMR), and confidence intervals for a selected number of causes of deaths are shown 
for men in the whole cohort (13 factories). The mortality from all causes and from the major causes of death is lower than expected on the basis of the general population experience, this deficit being particularly pronounced for the diseases of circulatory system (ICD 400-468). A statistically significant excess of deaths from accidents, poisonings, and violence (E810-E999) is observed. The excess does not appear to be directly related to the working environment as the specific causes of death for industrial accidents (E910-E918) are not in excess.

Scattered excesses based on small numbers are found for cancer of the larynx and benign neo- plasms. The excess of laryngeal cancer is limited to one of the 13 factories where four cases were observed versus 1.0 expected (SMR: $408 ; 95 \% \mathrm{CI}$ : 111-1024).

Table 4 gives the results for women in the whole cohort. The mortality from all causes is significantly lower than 100 and most of the specific causes of death show a deficit. The numbers of expected deaths, however, is very small for most of the specific sites of cancer and in particular for the sites of interest in this analysis. Results for women were consequently excluded from subsequent tables.

The results of the mortality analysis by time since

Table 4 Mortality analysis by cause of death for the total period of observation (women)

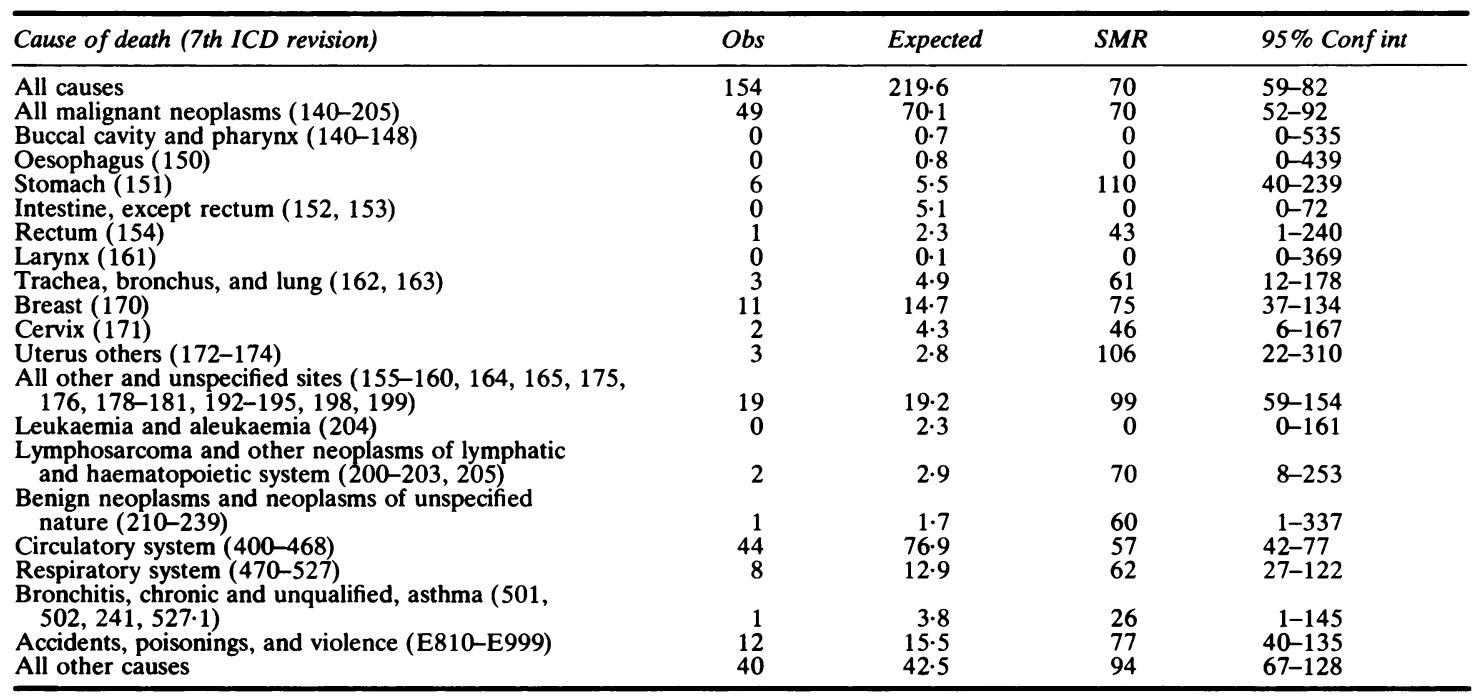

Table 5 Mortality analysis by time since first employment: rock wool production process (men)

\begin{tabular}{|c|c|c|c|c|}
\hline Time since first employment (years) & Observed & Expected & $S M R$ & $95 \%$ Conf int \\
\hline $\begin{array}{l}\text { All causes } \\
\leqslant 19 \\
20-29 \\
\geqslant 30 \\
\text { Total }\end{array}$ & $\begin{array}{l}515 \\
168 \\
123 \\
806\end{array}$ & $\begin{array}{l}524 \cdot 4 \\
171.4 \\
119 \cdot 8 \\
815 \cdot 6\end{array}$ & $\begin{array}{r}98 \\
98 \\
103 \\
99\end{array}$ & $\begin{array}{l}90-107 \\
84-114 \\
85-123 \\
92-106\end{array}$ \\
\hline $\begin{array}{l}\text { All neoplasms } \\
\leqslant 19 \\
20-29 \\
\geqslant 30 \\
\text { Total }\end{array}$ & $\begin{array}{r}126 \\
48 \\
35 \\
209\end{array}$ & $\begin{array}{r}128 \cdot 8 \\
41 \cdot 4 \\
27 \cdot 5 \\
197 \cdot 8\end{array}$ & $\begin{array}{r}98 \\
116 \\
127 \\
106\end{array}$ & $\begin{array}{l}82-117 \\
85-154 \\
87-117 \\
92-121\end{array}$ \\
\hline \multicolumn{5}{|l|}{$\begin{array}{l}\text { Cancer of the trachea, bronchus, } \\
\text { and lung }(162,163)\end{array}$} \\
\hline $\begin{array}{l}\leqslant 19 \\
20-29 \\
\geqslant 30 \\
\text { Total }\end{array}$ & $\begin{array}{l}27 \\
12 \\
11 \\
50\end{array}$ & $\begin{array}{r}29 \cdot 8 \\
9.7 \\
5 \cdot 7 \\
45 \cdot 1\end{array}$ & $\begin{array}{r}91 \\
124 \\
195 \\
111\end{array}$ & $\begin{array}{l}60-132 \\
64-217 \\
97-348 \\
82-146\end{array}$ \\
\hline \multicolumn{5}{|l|}{$\begin{array}{l}\text { Diseases of the respiratory system } \\
(470-527)\end{array}$} \\
\hline $\begin{array}{l}\leqslant 19 \\
20-29 \\
\geqslant 30 \\
\text { Total }\end{array}$ & $\begin{array}{r}18 \\
9 \\
11 \\
38\end{array}$ & $\begin{array}{r}25 \cdot 9 \\
11 \cdot 3 \\
8 \cdot 3 \\
45 \cdot 5\end{array}$ & $\begin{array}{r}69 \\
80 \\
133 \\
83\end{array}$ & $\begin{array}{l}41-110 \\
37-151 \\
66-238 \\
59-115\end{array}$ \\
\hline
\end{tabular}


first employment for the four causes or groups of causes of particular interest for the study-namely, all causes, all neoplasms (140-205), cancer of trachea, bronchus, and lung $(162,163)$, and for diseases of the respiratory system (470-527) are shown by type of production in tables 5-7. The mortality experience of that part of the cohort engaged in rock wool production (table 5) does not show any trend for all causes with time since first employment, but an increasing trend appears for the diseases of the respiratory system with a small excess, statistically not significant, after $\mathbf{3 0}$ or more years of observation.

A pattern of increase in SMR is also present for all neoplasms. The excess after 30 or more years since first employment is mainly due to an excess of lung cancer in that period. A clear pattern of increase in SMR is discernible for this site with time since first employment.

The data derived from the analysis by time since first employment in the glass wool production factories are shown in table 6 . No clear pattern or trend is discernible for any of the four causes or groups of causes of death. An excess of lung cancer, statistically not significant, is present after $\mathbf{3 0}$ or more years of observation.

The part of the cohort which had a working experience in the continuous filament production processes showed a $24 \%$ excess in total mortality, which is statistically significant (table 7). A large part of this excess is accounted for by a statistically significant excess for accidents, poisonings, and viol-

Table 6 Mortality analysis by time since furst employment: glass wool production process (men)

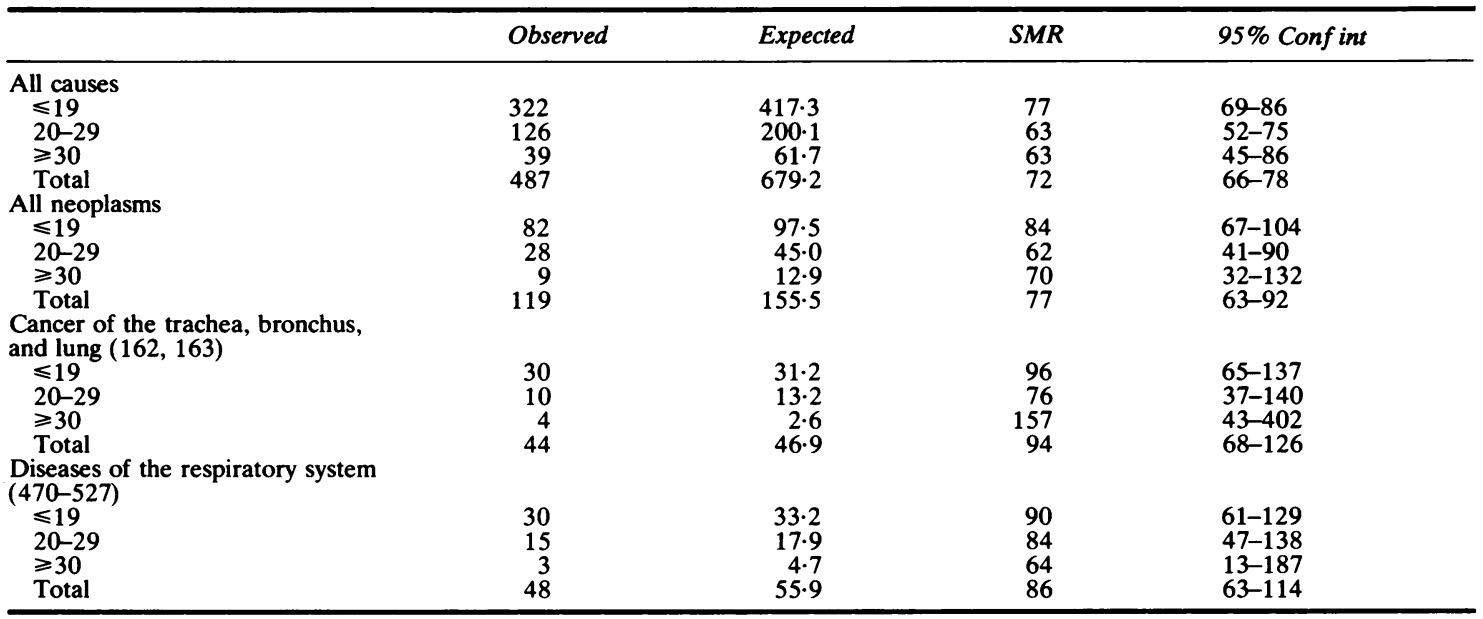

Table 7 Mortality analysis by time since furst employment: continuous filament process (men)

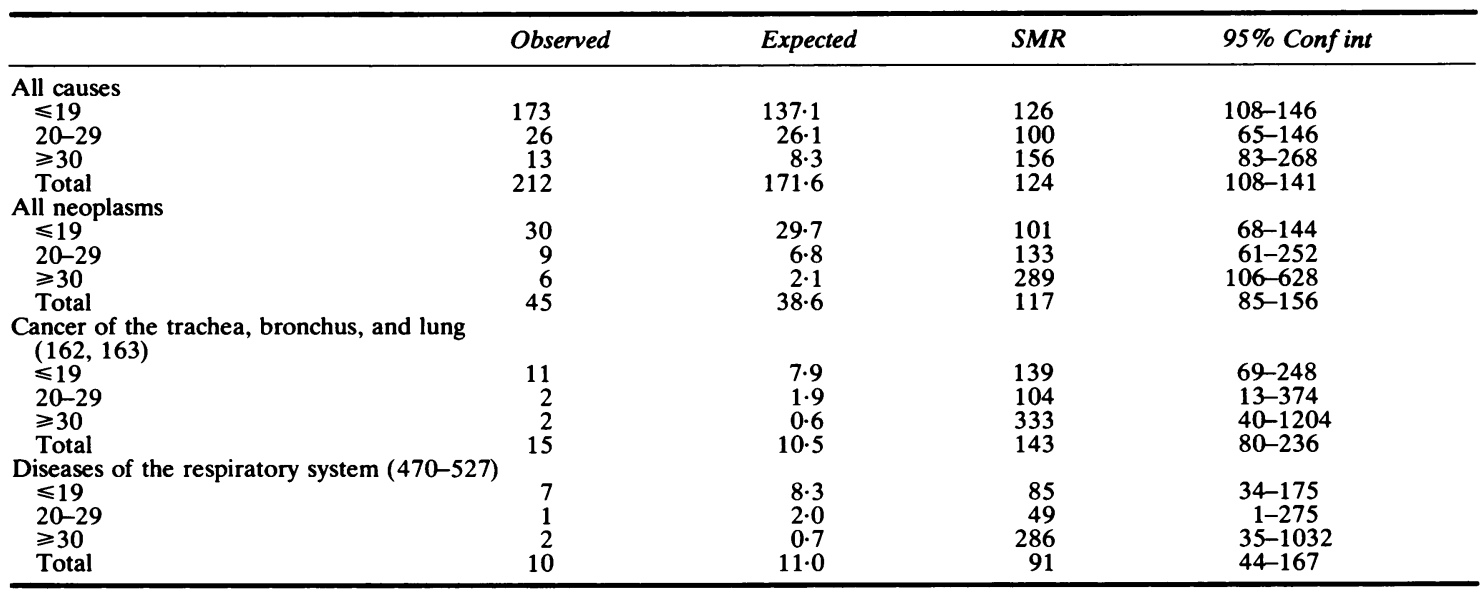


Table 8 Mortality for cancer of the trachea, bronchus, and lung by cumulative levels $(f \times$ years/ml) of exposure in workers with 20 or more years of observation

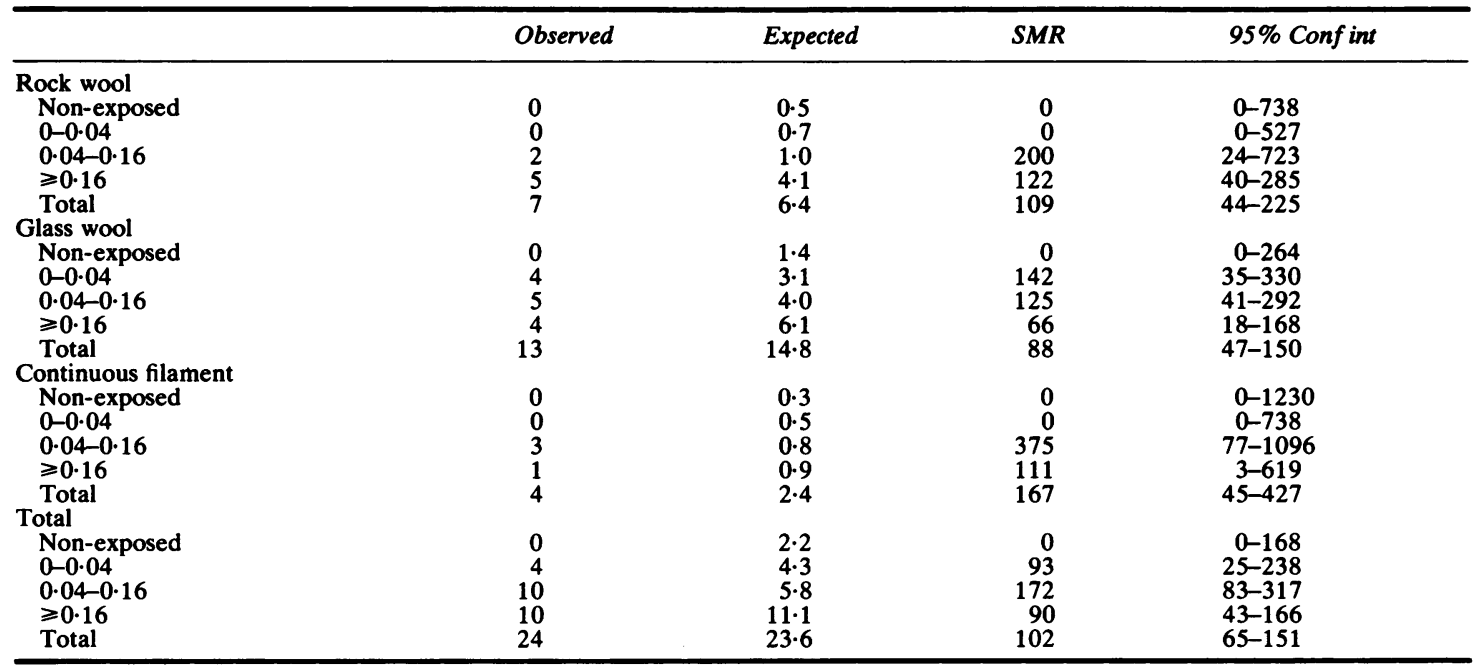

Table 9 Cancer incidence analysis by site for the total period of observation (men)

\begin{tabular}{lcrrr}
\hline Cause of death & Observed & Expected & SIR & 95\% Conf int \\
\hline All neoplasms (140-205) & 309 & $342 \cdot 9$ & 90 & $80-101$ \\
Buccal cavity and pharynx (140-148) & 14 & $12 \cdot 1$ & 116 & $63-195$ \\
Oesophagus (150) & 4 & $4 \cdot 2$ & 95 & $26-242$ \\
Stomach (151) & 32 & $30 \cdot 6$ & 105 & $72-148$ \\
Intestine, except rectum (152, 153) & 20 & $23 \cdot 4$ & 86 & $52-132$ \\
Rectum (154) & 21 & $17 \cdot 2$ & 122 & $76-187$ \\
Larynx (161) & 51 & $5 \cdot 1$ & 79 & $22-203$ \\
Trachea, bronchus, and lung (162,163) & 27 & $51 \cdot 1$ & 100 & $74-131$ \\
Prostate (177) & 27 & $31 \cdot 1$ & 66 & $43-96$ \\
Skin (190, 191) & 85 & 85 & $56-124$ \\
Other and unspecified (155-160,164, 165, 178-181, 192-195, & $98 \cdot 3$ & 87 & $69-107$ \\
$\quad$ Leuk-199) & 10 & $10 \cdot 3$ & 98 & $47-179$ \\
Lymphosarcoma and other neoplasms of lymphatic and haematopoietic \\
system (200-203, 205) & 14 & $17 \cdot 8$ & 79 & $43-132$ \\
\hline
\end{tabular}

SIR = Standardised incidence ratio.

Table 10 Cancer incidence lanalysis by time since first employment

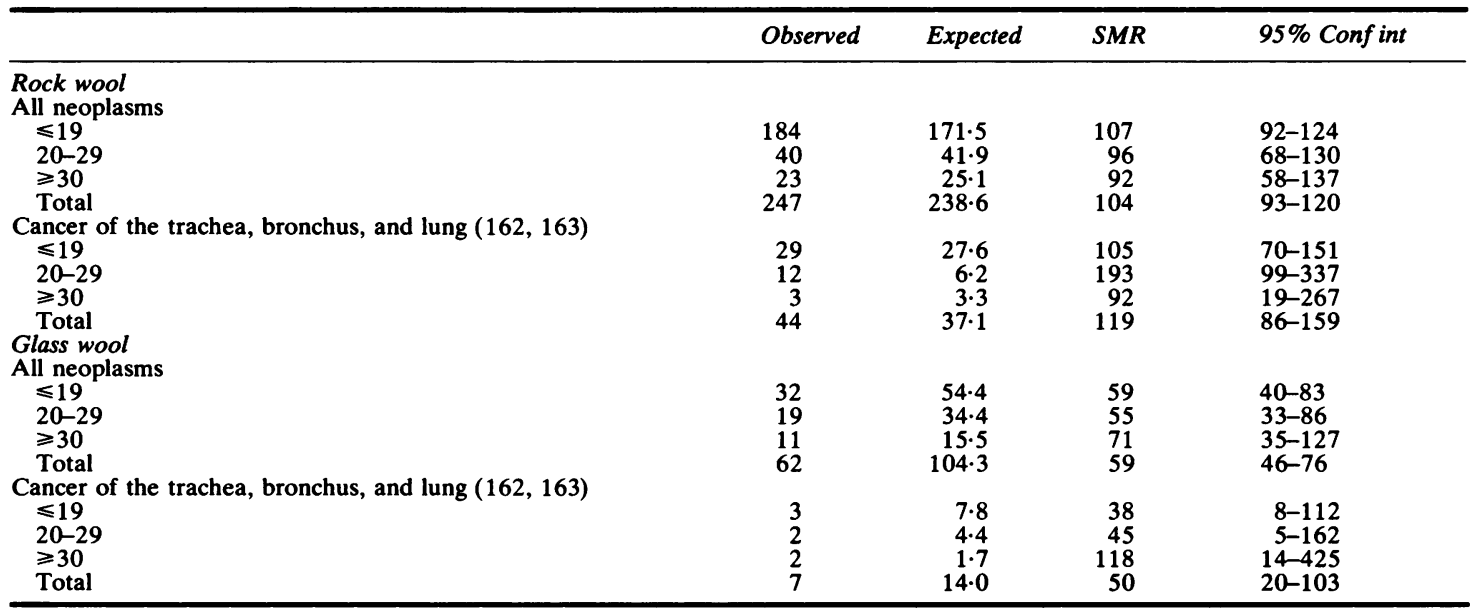


ence (E810-E999) (55 observed $v 30.8$ expected; SMR $=179 ; 95 \% \mathrm{CI}=135-233)$. A pattern of increase in SMR is present for all neoplasms, which display a statistically significant excess after $\mathbf{3 0}$ or more years since first employment. In particular, an excess, based on small numbers and statistically not significant, appears in this period for lung cancer. An excess is also present for diseases of the respiratory system. No trend of increasing SMRs, however, is discernible for these two causes of death with duration of observation.

Because of the excess shown in the previous tables, possible exposure-response relationships have been explored for cancer of the trachea, bronchus, and lung. This analysis has been confined to the part of the cohort with at least 20 years of observation as the most likely to show an effect, if any, from industrial exposure. The results in table 8 do not indicate an increasing trend of SMR with the index of cumulative exposure (as derived from present day airborne fibre concentrations); in fact the only raised SMR, close to statistical significance, is present in the group with medium cumulative exposure. None of the single industrial types of process exhibits a pattern of increasing SMRs with cumulative exposure, and scattered excesses which are present in some of the exposure subgroups are based on very small numbers. As may be inferred from the figures in table 8 compared with those in the previous tables, the size of the cohort suitable for the cumulative exposure-response analysis is smaller than the entire cohort. This is due to the absence of airborne fibre measurements in one factory and to missing information on the job type for a non-negligible number of individuals. In the additional case-control analysis of death from cancer of the trachea, bronchus, and lung no statistically significant trend of increasing risk with increasing duration of exposure (adjusted for time since first exposure) was found for any of the three production processes. For the three processes taken together the risk of cancer of the trachea, bronchus, and lung in men employed for six months to two years, two to seven years, and more than seven years, relative to the risk in men employed for less than six months were respectively $1.4(95 \% \mathrm{CI}=0.60-3.24), 1.9$ $(95 \% \mathrm{CI}=0 \cdot 87-4 \cdot 14)$, and $1.7(95 \% \mathrm{CI}=0.79$ 3.63).

\section{INCIDENCE OF CANCER}

The results of the analysis of cancer incidence in the nine factories in which it was feasible to carry this out are shown in tables 9 and 10. The SIR for all neoplasms is 90 , and for specific sites tends to be below 100 apart from buccal cavity and pharynx and rectum, which exhibit small, non-significant excesses.
Only rock wool and glass wool factories are represented in the cancer morbidity analysis and in neither is there an indication of an increasing SIR with time since first employment (table 10). In the rock wool factories an excess of cancer of trachea, bronchus, and lung is present in the group with $20-29$ years of observation, which is close to statistical significance.

\section{Discussion}

The 13 factories which it proved possible to include in this historical study cover reasonably well, particularly by production type, the range of factories in the initial European roster of 72 . Seven of the 15 countries in the initial roster are represented in the study. Two countries (Federal Republic of Germany and France), which included as much as one third of the plants in the initial roster, finished by being represented in the study by only one suitable factory. In both countries follow up was assessed as impossible or highly problematical. As a consequence of this type of impediment alone, five factories that could otherwise be included in the study had to be left out. It can be estimated that their inclusion would have increased the study population by some $30 \%$.

Cumulative levels of exposure, as derived from airborne fibre concentration measurements under present MMMF production conditions are low, generally in the range of 0.1 to $1-2 \mathrm{f} \times \mathrm{yrs} / \mathrm{ml}$. As previously noted, however, environmental fibre concentrations may have been higher in the past, perhaps by one order of magnitude. As a term of comparison it may be recalled that in those studies of the health effects of asbestos fibres in which fibre concentrations have been measured, cumulative exposures in the range from ten to several hundred $\mathrm{f} \times \mathrm{yrs} / \mathrm{ml}$ have usually been reported. Low exposure to an agent, while advantageous and desirable for workers' health, may make a biological response induced by the agent so inconspicuous as to be difficult or impossible to detect, even in a large study.

The mortality and cancer incidence analyses show no consistent departure across factories of the observed numbers from those expected on the basis of the general population experience for individual causes of death nor for individual cancer sites, with the exception of lung cancer (cancer of trachea, bronchus, and lung) discussed below. Only one death from mesothelioma was reported (factory C) out of a total of 309353 person-years computed for men and women. This case was a man aged 65 (at death) who had been employed for 92 days at the factory: about 11 years elapsed between first employment and death. 
Table 11 Lung cancer mortality by factory and by time since first employment (men)

\begin{tabular}{|c|c|c|c|c|c|c|c|c|c|c|c|c|}
\hline \multirow[t]{2}{*}{ Factory } & \multicolumn{3}{|l|}{$\leqslant 19$} & \multicolumn{3}{|c|}{$20-29$} & \multicolumn{3}{|l|}{$\geqslant 30$} & \multicolumn{3}{|l|}{ Total } \\
\hline & Obs & $\operatorname{Exp}$ & $S M R$ & $O b s$ & $\operatorname{Exp}$ & $S M R$ & $O b s$ & $\operatorname{Exp}$ & $S M R$ & Obs & $\operatorname{Exp}$ & $S M R$ \\
\hline \multicolumn{13}{|c|}{ Rock wool } \\
\hline C & 11 & $16 \cdot 8$ & 66 & 5 & $2 \cdot 7$ & 182 & 2 & 0.9 & 225 & 18 & $20 \cdot 4$ & 88 \\
\hline $\mathbf{G}$ & 3 & $2 \cdot 6$ & 114 & 0 & 0.6 & 0 & 0 & 0.0 & 0 & 3 & 3.2 & 93 \\
\hline $\mathrm{H}$ & 3 & 0.6 & 484 & 2 & 0.3 & 606 & 0 & $0 \cdot 2$ & 0 & 5 & $1 \cdot 2$ & 435 \\
\hline I & 0 & 0.6 & 0 & 0 & $0 \cdot 1$ & 0 & 0 & 0.0 & 0 & 0 & 0.7 & 0 \\
\hline $\mathbf{K}$ & 2 & $1 \cdot 0$ & 194 & 0 & 0.5 & 0 & 0 & $1 \cdot 2$ & 0 & 2 & $2 \cdot 7$ & 74 \\
\hline $\mathbf{M}$ & 2 & $1 \cdot 8$ & 110 & 1 & $1 \cdot 2$ & 85 & 3 & 0.8 & 395 & 6 & $3 \cdot 8$ & 160 \\
\hline \multicolumn{12}{|c|}{ Glass wool } & 121 \\
\hline B & 27 & $24 \cdot 2$ & 112 & 8 & $9 \cdot 2$ & 87 & 2 & $1 \cdot 0$ & 206 & 37 & 34.3 & 108 \\
\hline D & 1 & 3.3 & 30 & 2 & $2 \cdot 4$ & 84 & 2 & 1.4 & 148 & 5 & $\begin{array}{r}34.0 \\
7.0\end{array}$ & $\begin{array}{r}100 \\
71\end{array}$ \\
\hline $\bar{F}$ & 2 & $2 \cdot 7$ & 73 & 0 & $1 \cdot 3$ & 0 & 0 & 0.2 & 0 & 2 & $4 \cdot 2$ & 48 \\
\hline L & 0 & $1 \cdot 0$ & 0 & 0 & $0 \cdot 3$ & 0 & 0 & $0 \cdot 1$ & 0 & 0 & $1 \cdot 4$ & 0 \\
\hline \multicolumn{13}{|c|}{ Continuous filament } \\
\hline $\mathbf{J}$ & 5 & $4 \cdot 0$ & 126 & 0 & 0.4 & 0 & 0 & $0 \cdot 1$ & 0 & 5 & $4 \cdot 5$ & 111 \\
\hline
\end{tabular}

*Glass wool predominant till 1962, when discontinued.

The workforce of one factory (D) exhibit particularly low SMRs which contribute to the reduction, particularly for women, of all causes SMR for the entire cohort. This may be due to a pronounced "healthy worker effect," but before accepting this as the sole explanation, possible biases have been considered. Extensive checks of factory files make selection biases most unlikely, but incomplete ascertainment of death at old age in some subgroups of workers cannot be completely ruled out. Should this be the case, person-years and expected figures as reported in the present paper would somewhat overestimate and SMRs underestimate the corresponding true values.

If one takes all 13 factories together and pools the number of observed and expected deaths the risk of lung cancer appears to be increased 30 years after first employment, with an SMR of 192 (95\% confidence interval: 117-307; the data for individual factories are displayed in detail in table 11). The meaning of this statistically significant increase is not obvious but non-occupational or occupational confounding factors not controlled for in the study might have contributed to it. Among nonoccupational confounders a possible differential composition of the national reference population and of the workers' population in respect to urban/ rural residence, socioeconomic status, or general conditions of living may be important. National reference rates have been used in the seven countries for computing the expected number of deaths but those may not be entirely appropriate when rates vary widely within a country and the factory under study happens to be located in an area of particularly high or low mortality. In these conditions overestimation or underestimation of SMRs may be produced. For three countries (England,
Federal Republic of Germany, and Italy), local rates or local SMRs to be used as adjustment factors for the national rates were also available and were used for complementary analyses. The results of these analyses indicate that the use of local rates tends to lower the overall SMRs but do not appear to affect the ratios in the longest periods since first employment. No attempt to adjust further the national or local rates, or both, for social class has been possible.

Directly relevant among the potential nonoccupational confounders are smoking habits, which could not be taken into account as smoking histories for past workers, forming the great majority of the cohort, were not available. Though a difference in the distribution of smoking habits in the general population and in the workers' population may indeed exist or have existed in the past or both, such a difference (unless it is extreme) is unlikely to account entirely for an observed SMR of nearly $200 .{ }^{8}$

Among occupational confounders, particular attention should in principle be given to possible exposures to asbestos. An absence of asbestos processing or production was one of the main criteria for inclusion of the factories in the study, and in the light of all available information this requirement has been met for all but one factory. For this single rock wool factory information was disclosed (after the study results became available) that during certain periods asbestos was used in processing some products. It is unfortunately not possible to separate the possible effect of exposure to asbestos from any other effect due to the working environment. As the rock wool type of production is the one exhibiting a trend of increasing SMR for lung cancer with time since first employment (table 5) an alternative 
Table 12 Lung cancer analysis by time since first employment in the rock wool type of production excluding factory $O$ in which use of asbestos was reported

\begin{tabular}{lcccc}
\hline & Observed & Expected & SMR & $95 \%$ Conf int \\
\hline Cancer of trachea, bronchus, and lung (ICD & 162, & $163)$ \\
$\leqslant 19$ & 21 & $23 \cdot 4$ & 90 & $56-137$ \\
$20-29$ & 8 & $5 \cdot 4$ & 148 & $64-292$ \\
$\geqslant 30$ & 5 & $3 \cdot 1$ & 163 & $52-376$ \\
Total & 34 & $31 \cdot 9$ & 107 & $74-149$ \\
\hline
\end{tabular}

analysis was performed excluding the factory in which asbestos was processed. The results are presented in table 12, from which it appears that an increasing trend of SMRs with time since first employment is still present. The numbers are, however, smaller and the pattern is less evident.

If the observed excess in lung cancer is not due solely to uncontrolled confounders such as those just discussed, one would expect to find a relation with duration and amount of exposure as assessed by cumulative exposure as derived from present day airborne fibre concentrations in the MMMF working environment. No such relations are observed, but this must be viewed against the fact that, so far as the relation with cumulative exposure is concerned, only a part of the cohort was suitable for study. In addition, the small number of subjects followed up for 30 years or more prevents the evaluation of an exposure-response relationship restricted to the one period in which the excess was observed, 30 years since first employment. Similar limitations apply to the incidence of eancer. In fact there is no consistent excess in the incidence of lung cancer, as opposed to mortality, but this may be due to the small numbers available because incidence data are not collected in all countries. As for mortality, one may note in table 11 that when the expected numbers of deaths (30 years since first employment) is not too small (in practice bigger than 0.50) the SMR appears systematically raised. This, and the fact that the observed excess occurs at a site (the lung) and at a time (several decades after first employment) in which an effect, if any, could be a priori expected to show up, points towards a causal role of MMMF or of the other exposures to, for instance, binders such as bitumen, mineral oils, and phenolic resins or to fumes occurring in the MMMF production industry or a combination of these.

These findings need to be placed against the background of the other scientific evidence at present available on the issue of the carcinogenic effect of MMMF. Three epidemiological studies of limited dimension have reported no excess in lung cancer mortality, ${ }^{9-11}$ and two have reported rises of SMRs that are not statistically significant. Shannon reports an observed/expected ratio for deaths from lung cancer of $1.4(7 / 4.22),{ }^{12}$ and Morgan a ratio of 1.4 $(37 / 27 \cdot 3)$ with a ratio of $1.5(9 / 5.91)$ for workers exposed at least 20 years and observed at least 30 years. ${ }^{13}$

An investigation similar to the present study and involving 16730 workers at 17 MMMF producing plants has been carried out within the United States by Enterline and Marsh. ${ }^{14}$ The age structure of the workforce in their study is, however, somewhat older, and the follow up longer than in the present study; the total number of deaths observed in the United States study is $3761 v 1659$ observed in the European study. The average duration of employment is about five years in our study and about 11 years in the United States investigation. In that study 202 deaths from lung cancer were observed among glass wool workers $v 203.5$ expected for the whole period of observation, and 47 deaths from lung cancer were observed $v 36.0$ expected for workers with at least 30 years of observation. The corresponding figures for slag wool/rock wool workers were 45 observed $v 28.1$ expected and 14 observed $v 8.1$ expected. No clear relation to cumulative exposure to man made mineral fibres was present.

Experimental data indicate clearly that a carcinogenic effect can be induced by direct intrapleural administration of MMMF, ${ }^{34}$ and one experiment suggests that tumours may also be produced by intratracheal administration (F Pott et al at 6th International Pneumoconiosis Conference, Bochum, September 1983). On the other hand, no carcinogenic effect has been detected in inhalation studies. ${ }^{15}$

Even when seen in the light of the ensemble of results from published reports, our study cannot settle the question as to whether the observed result of an excess of lung cancer 30 years after first employment can be attributed to exposure to MMMF. The result is, however, suggestive of an increased risk associated with the MMMF working environment of 30 or more years ago. Further follow up of workers and environmental investigations are already in progress to clarify this critical issue.

We acknowledge with thanks the support of the Joint European Medical Research Board, a registered charity founded by the MMMF industry, and the collaboration of numerous people at each of the factories included in the study. Professor J Peto, London, kindly provided the computer program for modified life table analyses. The feasibility phase of the study was carried out in collaboration with $\mathrm{Dr} J$ Milne, Melbourne. 
Requests for reprints to: Dr R Saracci, chief, Unit of Analytical Epidemiology, Division of Epidemiology and Biostatistics, International Agency for Research on Cancer, 150 cours Albert Thomas, 69372 Lyon Cedex 08, France.

\section{References}

' World Health Organisation. Biological effects of man-made mineral fibres. Copenhagen: WHO, 1983;10-1. (Euro reports and studies 81.)

${ }^{2}$ Kuschner M, Wright GW. The effects of intratracheal instillation of glass fiber of varying size in guinea-pigs. In: Occupational exposure to fibrous glass. Washington DC: National Institute for Occupational Safety and Health, 1976;151-68. (US Department of Health, Education, and Welfare Publication No (NIOSH, 76-151).)

${ }^{3}$ Stanton MF, Wrench C. Mechanisms of mesothelioma induction with asbestos and fibrous glass. J Natl Cancer Inst 1972; 48: 797-821.

4 Pott F, Friederichs KH. Tumoren der Ratten nach ip Injektion faserformiger Staube. Naturwissenschaften 1972;59:318.

${ }^{5}$ Saracci R. Epidemiology of groups exposed to other mineral fibres. In: Wagner JC, ed. Biological effects of mineral fibres. Vol 2. Lyon: IARC, 1980;951-63. (Scientific publication No 30.)

- Ottery J, Dodgson J, Harrison GE, Cherrie JW. Short-term surveys of airborne fibres in European manufacturing plants. In: WHO-EURO, Biological effects of man-made mineral fibres occupational health conference, proceedings of the conference.
Copenhagen: World Health Organisation (in press).

${ }^{7}$ Ottery J. Report on the environmental investigation at Rockwool $A / B$ Skovde. Edinburgh: 1981. Institute of Occupational Medicine, IOM internal document No BP 31075/2/B(4)13.1.

${ }^{8}$ Axelson $\mathrm{O}$. Aspects of confounding in occupational health epidemiology. Scand J Work Environ Health 1978;4:85-9.

${ }^{9}$ Bayliss DL, Dement JM, Wagoner JK, Blejer HP. Mortality patterns among fibrous glass production workers. Ann NY Acad Sci 1976;271:324-35.

${ }^{10}$ Enterline PE, Henderson V. The health of retired fibrous glass workers. Arch Environ Health 1975;30:113-6.

"Robinson CF, Dement JM, Ness GO, Waxweiler RJ. Mortality patterns of rock and slag mineral wool production workers: an epidemiological and environmental study. $\mathrm{Br} \mathrm{J}$ Ind Med 1982;39:45-53.

${ }^{12}$ Shannon H, Hayes M, Julien J, Muir D. Mortality experience of glass fibre workers. In: WHO-EURO Biological effects of man-made mineral fibres, occupational health conference, proceedings of the conference. Copenhagen: World Health Organisation (in press).

${ }^{13}$ Morgan RW, Kaplan SD, Bratsberg JA. Mortality among fibrous glass production workers. In: WHO-EURO, Biological effects of man-made mineral fibres, occupational health conference, proceedings of the conference. Copenhagen: World Health Organisation (in press).

14 Enterline PE, Marsh GM. Mortality of workers in the MMMF industry. In: WHO-EURO, Biological effects of man-made mineral fibres, occupational health conference, proceedings of the conference. Copenhagen: World Health Organisation (in press).

is World Health Organisation. Biological effects of man-made mineral fibres. Copenhagen: WHO, 1983;32-40. (Euro reports and studies 81 .) 